\title{
Partillando uma vida de cão: Políticas públicas e A LEISHMANIOSE VISCERAL CANINA
}

\author{
Adriana Leal ABREU ${ }^{*}$ \\ Jean SEGATA* \\ Bernardo LEWGOY***
}

RESUMO: Este artigo apresenta algumas linhas introdutórias de uma exploração sobre políticas públicas para a Leishmaniose Visceral Canina. A partir do caso de Porto Alegre-RS procuramos mostrar que há um silenciamento do sofrimento canino na evidência de que políticas públicas para Leishmaniose passam a ser constituídas apenas quando a doença ameaça vidas humanas. Igualmente, mostramos como políticas de coexistência são produzidas e vividas muito mais a partir da iniciativa civil, quase sempre à margem e até mesmo contra as políticas públicas pensadas e executadas pelo Estado, quando certas populações de cães e de humanos são negligenciados pelo poder público.

PALAVRAS-ChAVE: Leishmaniose Visceral Canina. Políticas Públicas. Doenças negligenciadas. Saúde multiespécie.

Introdução

A Leishmaniose Visceral Canina é uma doença que acomete cães e humanos. Ela é transmitida por um flebotomíneo conhecido como mosquito-palha. Ao alimentarse de sangue de algum mamífero, preferencialmente o cão, o flebótomo contaminado

\footnotetext{
* UFRGS - Universidade Federal do Rio Grande do Sul. Programa de Pós-Graduação em Políticas Públicas. Porto Alegre - RS - Brasil. 91509-900 - adrianalealabreu@gmail.com. https://orcid.org/0000-0002-60135746.

** UFRGS - Universidade Federal do Rio Grande do Sul. Programa de Pós-Graduação em Políticas Públicas. Porto Alegre - RS - Brasil. 91509-900 - jeansegata@ufrgs.br. http://orcid.org/0000-0002-2544-0745.

*** UFRGS - Universidade Federal do Rio Grande do Sul. Programa de Pós-Graduação em Políticas Públicas. Porto Alegre - RS - Brasil. 91509-900 - mlewgoy.bernardo@gmail.com. https://orcid.org/0000-00017455-6050.
} 
deposita nele a leishmania - o protozoário responsável pelo desenvolvimento da doença. Por isso cães são tratados como uma espécie de reservatório natural da doença em áreas urbanas. Em algum casos, cães já adoecidos podem ser picados por estes flebotomíneos, que por sua vez podem transmitir a doença ao picar outros mamíferos, como os humanos. Para humanos, a Leishmaniose é uma doença curável, reconhecida pelo Estado e cujo tratamento é gratuito para todos os cidadãos que acessam a rede pública de saúde. Para os cães, a Leishmaniose ainda é lamentavelmente fatal, uma vez que as disputas sobre haver uma cura reconhecida ainda formam uma questão em aberto, mesmo que muitos veterinários já a promovam de forma clínica e reduzam as taxas de leishmania nos cães até uma medida indetectável nos métodos tradicionais de coleta e diagnóstico.

Além disso, a Leishmaniose Visceral Canina é parte de uma família mais ampla de leishmanioses (que inclui ainda as tegumentares) e cuja unidade analítica levou muito tempo para ser estabilizada nas redes científicas numa longa elaboração que envolveu assimetrias e apagamentos, conforme apontam Benchimol e Jogas Junior (2020). Mas, ainda que as leishmanioses sejam consideradas doenças negligenciadas do ponto de vista da Organização Mundial da Saúde (OMS), no Brasil elas continuam em desenvolvimento. Assim, apenas recentemente elas se tornaram um objeto de pesquisa altamente especializada da ciência biomédica, sendo por isso um tema ainda mais desafiador do ponto de vista da pesquisa social e histórica (Benchimol; Jogas Junior, 2020).

Contudo, o que queremos mostrar neste artigo é que para além da mecânica biológica do ciclo da doença e do desinteresse do Estado para o seu tratamento, a Leishmaniose Visceral Canina envolve ainda relações mais complexas, que não são capturadas pelas políticas públicas vigentes. Ela entrelaça uma cadeia multiespécie de entes como protozoários, humanos, cães, vetores e ambientes com uma ampla rede sociotécnica onde circulam conhecimentos, agentes e autoridades de saúde pública, corporações farmacêuticas e produtoras de testes, vacinas, telas e medicamentos, mas também veterinários privados e tutores de animais. Assim, com pesquisas etnográficas a partir da situação de Porto Alegre-RS e de análises de campanhas e intervenção de agentes de saúde pública locais e nacionais, buscamos entender como as mensagens e implicações morais das definições de risco e doença são subjetivadas e reelaboradas por moradores de bairros periféricos e tutores de cães com leishmaniose. Neste caso, nos interessamos em entender como se produz uma certa subjetivação moral do risco e a sua relação com políticas públicas de combate a doença e sua articulação com discursos emergentes de posse responsável, biossegurança e saúde única. Além disso, nos preocupamos em destacar o papel destes diferentes atores na produção de definições 
sociais e reelaborações dos sentidos de doença, saúde e convívio entre espécies e ambientes. De modo mais particular, lançaremos neste artigo algumas linhas introdutórias de uma exploração sobre dois tópicos: (i) o modo como se silencia o sofrimento canino na evidência de que políticas públicas para a Leishmaniose Visceral Canina passam a ser constituídas apenas quando a doença ameaça vidas humanas e (ii) como políticas de coexistência são produzidas e vividas muito mais a partir da iniciativa civil, quase sempre à margem e até mesmo contra as políticas públicas pensadas e executadas pelo Estado.

\section{A Leishmaniose em Porto Alegre-RS}

Parte do trabalho etnográfico que desenvolvemos entre 2016 e 2019 em Porto Alegre-RS envolveu mapear e descrever as ações para o monitoramento e controle da Leishmaniose Visceral Canina, capitaneadas pela Secretaria Municipal da Saúde e sua Coordenadoria de Vigilância em Saúde. Para tanto, analisamos os relatórios de gestão que esta secretaria emitiu entre 2009 e 2019 e que estão disponibilizados no seu website para consulta pública (PORTO ALEGRE, 2020a). Sem adentrar aqui nos pormenores deste material, cabe ressaltar que foi em 2010 que Porto Alegre teve seu primeiro caso canino da doença. Desde lá, já foram diagnosticados 285 cães com Leishmaniose Visceral Canina. Entre humanos as ocorrências começaram a aparecer em 2016 e desde então surgiram 11 casos, sendo quatro deles somente no ano de 2018, uma ano após a doença estampar os jornais da cidade e animar as discussões na esfera pública. A bem da verdade, a repercussão maior veio no outono de 2017, quando uma polêmica ganhou lugar nos noticiários e na opinião pública de Porto Alegre-RS e acirrou as disputas em tono desta doença. O que se dizia era que a prefeitura municipal havia contratado uma clínica veterinária para a realizar a eutanásia de trezentos cães soropositivos para Leishmaniose Visceral Canina. Em poucos dias, lideranças de movimentos de proteção, apoiados por políticos ligados à chamada "causa animal", acionaram a justiça a fim de buscar meio para impedir o que consideravam uma matança. Segundo o processo licitatório, tratava-se de um contrato que permitiria que uma determinada clínica realizasse a prestação de serviço de eutanásia de até 300 cães, ainda que não fosse este, concretamente, o número total de animais já encaminhados para o procedimento. No entanto, a repercussão entre as lideranças da proteção animal fez com que a contratação da clínica fosse revogada e com ela também suspensa a eutanásia dos cães (CANOFRE, 2017; PORTO ALEGRE, 2017a). 
Conforme reportado no mencionado relatório de gestão, o ano de 2016 é aquele delimita o marco zero para a Leishmaniose na cidade de Porto Alegre-RS. Isso, porque foi neste ano que se reportou o primeiro caso humano - e por conseguinte, quando a doença passou a ganhar importância para as autoridades de saúde:

Em outubro de 2016 a EVDT recebeu a notificação de um caso confirmado de Leishmaniose Visceral Humana internada no Hospital de Clínicas. A investigação concluiu que se tratava de um caso autóctone do bairro Protásio Alves (Gerência Leste/Nordeste). A partir da notificação foi emitido um novo Alerta Epidemiológico sobre a autoctonia da doença em Porto Alegre. Desde então ocorreram mais dois casos suspeitos, ambos descartados por sorologia e biópsia de medula Além disso, inúmeras ações (capacitações, vistorias, análise sorológica de cães, sensibilização da comunidade) foram desenvolvidas pela CGVS e outras secretarias naquela comunidade e Gerência Distrital. Desde então ocorreu à notificação de mais um caso, que foi descartado. Em 03 de outubro, devido à situação de emergência foi realizada uma reunião com as equipes envolvidas com a doença e decidido criar a sala de situação da LV que já ficou marcada para o dia 07/10/2016 com periodicidade das reuniões semanais. Em 09 de novembro de 2016 foi publicada a Portaria Municipal 1438/16 que declara Emergência em Saúde Pública de Interesse Municipal (Porto Alegre, 2016, p.260).

Foi também em 2016, diante da detecção da autoctonia da doença que se deu início às ações de capacitação dos agentes comunitários na região da gerência de saúde onde ocorreu o primeiro caso humano e onde ocorreram, concomitantemente, os casos caninos. Neste relatório consta o registro de capacitação de 63 agentes comunitários de saúde. Este marco para o início da política pública de controle da Leishmaniose Visceral no município de Porto Alegre-RS tem, claramente, como balizador, a saúde humana. A saúde animal de forma particular ou independente ou aquela dos ambientes que ambos partilham ainda seria objeto de discussões que culminariam em uma carta aberta à população.

No dia 23 de maio de 2017, diversas organizações de saúde humana e não humana reuniram-se e assinaram um documento considerando as práticas que seriam acordadas entre elas e que vigorariam a partir de então para o monitoramento e controle da Leishmaniose Visceral Canina em Porto Alegre-RS. Na então chamada Carta Aberta à População de Porto Alegre sobre Leishmaniose Visceral Humana (PORTO ALEGRE, 2017a), foram elencadas três grandes áreas de atuação:

1. Manejo da Leishmaniose Visceral Humana em Porto Alegre. Nele, estão incluídos a distribuição de testes rápidos para diagnóstico da doença em áreas 
estratégicas, a capacitação de profissionais e a instituição de fluxo de investigação diagnóstica e de manejo de casos buscando diagnósticos precoces e redução da letalidade;

2. Medidas intersetoriais descentralizadas e de abordagem local para combate aos vetores e rompimento da cadeia de transmissão. Neste tópico foram acordadas diversas medidas intersetoriais descentralizadas e de abordagem local com o objetivo de combate aos vetores e rompimento da cadeia de transmissão. Essas ações estão divididas em quatro áreas:

i. Ações gerenciais, foram emergenciais na ocasião em que os casos humanos foram ocorrendo e necessitaram de atenção mais direta dos órgãos de saúde;

ii. Ações de vigilância epidemiológica que incluíram investigações minuciosas dos casos por meio de busca ativa pela equipe de atenção primária; realização de teste rápido ou solicitação de exame sorológico; visitas às moradias afetadas; emissão de alertas epidemiológicos para os Serviços de Saúde após a confirmação dos óbitos humanos e; reunião com os serviços de saúde envolvidos nos casos para aprimoramento da identificação de casos com clínica semelhante/compatível na área próxima;

iii. Ações de vigilância ambiental com instalação de armadilhas para a captura de vetores seguindo o modelo de sucesso aplicado controle do Aedes aegypti, já analisado por Vargas (2018) e Segata (2019) e; ampla mobilização comunitária e intersetorial para a identificação de áreas de risco de proliferação de flebotomíneos por meio de acúmulo de materiais sólidos, umidade excessiva, acúmulo de dejeitos e de animais suspeitos com envolvimento de órgãos municipais para limpeza local e capina de mato;

iv. Ações educacionais por meio da capacitação dos profissionais das áreas de risco quanto a identificação de pacientes com risco e suspeita de Leishmaniose, bem como; a capacitação dos Agentes Comunitários de Saúde e informação à população e ao Controle Social acerca da Leishmaniose Visceral Humana, seus sintomas e consequências, sua cadeia de transmissão e cuidados coletivos e individuais necessários para bloqueio da transmissão da doença, com foco principal no vetor.

\section{Medidas acordadas pelos entes relativas a Leishmaniose Visceral}

Canina. Aqui se destaca o método de diagnóstico da infecção por Leishmaniose em cães. Ele exige dois testes positivos realizados sequencialmente: o Teste Rápido Qualitativo para a detecção de Anticorpos de Cão para a Leishmania (TR-DPP BioManguinhos/Fiocruz) positivo com confirmação sequencial feita pelo Teste 
Imunoenzimático (Elisa/Fiocruz). A combinação positiva de ambos seria suficiente para conferir status de infecção por Leishmaniose Visceral Canina. Contudo, chama também a atenção da conduta da Secretaria Municipal da Saúde frente aos cães com diagnóstico confirmado de Leishmaniose Visceral Canina. Foi consenso entre os presentes na reunião que culminou na Carta Aberta, que como medida de saúde pública e de acordo com a missão primordial em defesa da vida humana e do marco legal que rege as secretarias estadual e municipal de saúde, "os cães com Leishmaniose Visceral Canina deveriam ser submetidos à eutanásia". Ou seja, apesar da consideração de algumas exceções, como bem mostraram Lewgoy, Mastrangelo e Beck (2020), a biossegurança é inimiga da vida e, no contexto específico da Leishmaniose, impera como última força a tanatopolítica. Em termos de exceções à prática da eutanásia em cães soropositivos para Leishmaniose cabe mencionar a previsão legal de responsabilidade assumida por tutores ou guardiões sobre seus cães desde que atendam integralmente exigências como a assinatura de termo de responsabilidade e ciência (que também deve ser assinado por veterinário responsável pelos cuidados do cão), onde deve ainda constar a localização do animal e a descrição do seu tratamento, contendo especificações quanto ao lote e dosagem de medicamento a base de miltefosina. Também são requeridos o uso ininterrupto de coleira impregnada por detametrina a $4 \%$ ou equivalente (trocada a cada 4 meses) e, eventualmente, afastamento de áreas silvestres com atuação de flebotomíneos e até o monitoramento do animal por microchipagem (se for do interesse da Secretaria de Saúde, como passou a ocorrer em 2019), entre outras exigências (PORTO ALEGRE, 2017a).

É interessante ainda ressaltar que quando analisados os relatórios de gestão da Prefeitura Municipal de Porto Alegre, apenas constam dados mais específicos sobre a Leishmaniose Visceral Canina a partir do ano de 2016. Isso se justifica, como já explicitado anteriormente, que este foi o ano em que houve o aumento dos casos humanos na cidade. Isso acendeu os alertas epidemiológicos e produziu uma movimentação total de todas as entidades que subscreveram no ano seguinte a Carta Aberta. A tabela que trazemos abaixo sintetiza alguns dados destes relatórios (PORTO ALEGRE, 2020b). 
Tabela 1 - Dados das ações de Leishmaniose Visceral Canina relativos aos relatórios de 2016 a 2019

\begin{tabular}{|c|c|c|c|c|}
\hline \multirow{2}{*}{ Atividade } & \multicolumn{4}{|c|}{ Períodos Analisados } \\
\hline & 2019 & 2018 & 2017 & 2016 \\
\hline $\mathrm{N}^{\mathrm{o}}$ de notificações de LVC por serviços veterinários & 84 & 47 & 45 & 427 \\
\hline $\mathrm{N}^{o}$ de coletas realizadas para $\mathrm{LVC}$ & 864 & 1081 & 1005 & 383 \\
\hline Coleiras antiparasitárias entregues á comunidade & 668 & 694 & 762 & 82 \\
\hline Coleiras antiparasitárias entregues á SMAMS/SEDA & 140 & 130 & 200 & 0 \\
\hline Total de Coleiras Distribuídas & 808 & 824 & 962 & 82 \\
\hline $\mathrm{N}^{\mathrm{o}}$ de amostras enviadas ao LACEN para exame sorológico de LVC & 77 & 288 & 164 & 115 \\
\hline $\mathrm{N}^{\mathrm{o}}$ de TR realizados & 835 & 1064 & 945 & 0 \\
\hline $\mathrm{N}^{0}$ de TR positivos & 150 & 168 & 125 & 70 \\
\hline Total de Testes Rápidos Realizados & 985 & 1232 & 1070 & 70 \\
\hline Cães positivos LVC - ELISA/LACEN & 59 & 139 & 100 & 67 \\
\hline Cães ainda aguardando resultado LACEN(novo) & 80 & 0 & 4 & 0 \\
\hline Cães testados positivos & 139 & 139 & 104 & 67 \\
\hline Eutanásia de cães sororreagentes pelo proprietário & 10 & 22 & 0 & 0 \\
\hline Eutanásia de cães sororreagentes pela CGVS/SMS & 38 & 47 & 0 & 0 \\
\hline Eutanásias Realizadas & 48 & 69 & 0 & \\
\hline Reuniões técnicas LVC & 0 & 9 & 42 & 15 \\
\hline $\mathrm{N}^{\mathrm{o}}$ de orientações dadas para LVC & 0 & 72 & 261 & 93 \\
\hline $\mathrm{N}^{\mathrm{o}}$ de cães microchipados & 555 & 0 & 0 & 0 \\
\hline
\end{tabular}

Fonte: Elaborada pelos autores com base nos Relatórios de Gestão da Secretaria Municipal de Saúde de Porto Alegre.

Como pode ser observado na compilação das tabelas apresentadas nos relatórios de gestão de 2016 a 2019, mesmo com a autorização judicial para realização das eutanásias em 2017, essa prática não é crescente no município de Porto Alegre-RS. Observa-se que em 2018 ocorreram 69 eutanásias contra 48 no ano de 2019, sendo que em 2018, do total dos procedimentos, 22 deles foram realizados pelos proprietários e em 2019, apenas 10 eutanásias foram realizadas pelos proprietários. Nestes mesmos anos, o poder público realizou 47 procedimentos em 2018 e 38 em $2019^{1}$. Outro aspecto importante é a distribuição de coleiras parasitárias e a microchipagem de cães. Com relação a distribuição de coleiras, mesmo em decréscimo, esta é uma prática bastante positiva indo ao encontro de estudos que confirmam redução de contaminação de outros cães quando os soropositivos não eutanasiados são encoleirados. Como os dados não são específicos não podemos dizer que os cães encoleirados contribuíram para redução da contaminação no município de Porto Alegre-RS já que nos relatórios não apresentam

\footnotetext{
${ }^{1}$ Não se pode julgar que esta prática é uniforme pois existem poucos dados acerca dos procedimentos e como não tivemos acesso aos prontuários físicos dos cães, não podemos afirmar quais as suas condições clínicas, se eram ou não sintomáticos e em que áreas estavam localizados.
} 
as regiões onde estes cães estão nem foram apresentados dados estatísticos dessa possível redução.

No geral, percebeu-se nos relatórios pouco detalhamento sobre as políticas de controle da Leishmaniose Visceral Canina. Ainda que eles tragam a informação que os casos caninos precedem os humanos, informações quanto as práticas existentes no Município para o controle da zoonose são difusas e centradas no controle dos caninos soropositivos ou dos flebotomíneos. Estes últimos possuem mesmo uma sessão própria nos relatórios analisados. A sessão vigilância de Flebotomíneos (Vetores LV e LTA) é apresentada nos relatórios analisados 2016 a 2019.

Ecos do mosquitocentrismo, para usar uma expressão que sumariza uma problemática recalcitrante do universo das doenças vetoriais no Brasil (Segata, 2019), também são evidentes no relatório. Segundo o relatório de 2017, houve um aumento de investigações entomológicas partindo de $42 \mathrm{em}$ 2016, para 71 em 2017. Esse aumento deveu-se em função da confirmação de novos casos caninos em áreas distintas das notificações anteriores e também em função dos casos autóctones humanos. O relatório informa que em 2017 foram analisadas 625 amostras de insetos e identificados 583 flebotomíneos. No ano de 2018 houve queda do número de investigações em virtude da baixa do número de casos humanos. Em 2017 foram 71 investigações, já em 2018 ocorreram apenas 41 investigações. Outro aspectos destacado no relatório de 2018 é que os pacientes habitavam áreas cuja fauna já era conhecida de flebotomíneos, não necessitando de novas coletas. A espécie "incriminada" como sendo o vetor urbano, a Lutzomya Longipalpis, não foi encontrada no município de Porto Alegre-RS, nos anos de 2016, 2017 e 2018, conforme é apresentado no Relatório de Gestão da Secretaria Municipal de Saúde. Todavia, nestes três anos as espécies consideradas importantes por sua frequência de identificação foram Lutzomyia Gaminarai, Pintomyia Fischeri e Mogonemyia Migonei, todas localizadas em áreas silvestres.

É importante salientar que o estreitamento entre as faunas silvestres e o homem vem se agravando diariamente, seja por ocupações irregulares ou por empreendimentos imobiliários cada vez mais afastados dos aglomerados centros das metrópoles. Com relação a essa impossibilidade de construir moradias de forma horizontal e "mais saudáveis" muitas pessoas buscam no campo uma nova forma de viver nas cidades em áreas que antes eram florestas. Nos bairros mais afastados do centro de Porto AlegreRS, por exemplo, são cada vez mais comuns condomínios de luxo dividindo espaço com invasões, demonstrando não apenas o abismo socioecônomico que divide camadas da população, como a flagrante invasão das áreas silvestres. Não obstante, assinalam Roque e Jansen (2014), os ciclos de transmissão de diversas espécies de parasitos sempre ocorreram e assim continuam. O que tem se tornado um problema de saúde 
pública é o fato de que o homem e seus animais domésticos estão cada vez mais próximos destas áreas silvestres, facilitando o intercâmbio de doenças que antes eram invisibilizadas sob a forma de problemas do interior. Essas transformações ambientais não naturais trazem reflexos negativos tanto para humanos, quanto para a vida de parasitos, vetores e outras espécies que antes não eram "problema". Roque e Jansen (2014) também ressaltam a importância de verificar a potencialidade de gambás, roedores e outras espécies "domésticas" como sendo reservatórios para a Leishmania do tipo Infantum e sua eventual participação nos ciclos de transmissão já que seu ambiente é adaptado desde troncos de árvores até forros de habitações humanas.

$\mathrm{O}$ que nos faz refletir sobre o caso da Leishamniose Visceral entre humana como que causada pela Leishmania Infantum é a ideia de que os cães talvez não sejam os únicos reservatórios disponíveis da doença. As atuais políticas de manutenção do parasito tendem a sugerir a eliminação de cães soropositivos - em muitos municípios brasileiros sendo esta ainda a forma exclusiva de controle da Leishmaniose. Mas, seguindo os argumentos de Roque e Jansen (2014) esta é uma prática que tende a ignorar completamente a possibilidade de participação de outros mamíferos silvestres e sinantrótipos infectados que podem se aproximar de áreas domiciliadas e servir de fonte de infecção do vetor. Isso, segundo os autores, sugere que uma mudança de paradigmas na pesquisa e a vigilância de reservatórios silvestres dessa parasitose seja necessária e urgente (PORTO ALEGRE, 2017b).

O que fica saliente é que a Leishmaniose passa a compor a agenda das políticas públicas de saúde em Porto Alegre-RS apenas quando atinge os humanos e as formas mais robustas para a sua atenção ficam vão da eutanásia canina ao controle do vetor, ao invés de um exame mais aprofundado da complexa relação entre humanos, cães, flebotomíneos e os ambientes que constituem e que partilham.

\section{Mais além das políticas públicas}

Por diferentes caminhos, temos buscado em nossas pesquisas ressaltar o lugar proeminente dos animais nas relações que constituem com seus companheiros humanos. O caso daquela que resultou neste trabalho não foi diferente. Em cena, está a tensão entre a convivência e o contágio, especialmente evidenciada quando animais de companhia também podem oferecer algum tipo de "risco" para a saúde humana, como no caso da Leishmaniose Visceral Canina. Para alargar a compreensão da relação entre humanos e animais no contexto desta doença, a pesquisa não acompanhou apenas as políticas públicas, mas também as experiência de partilha entre animais soropositivos e 
seus companheiros humanos. Parte desta frente de pesquisa se deu por meio do ingresso em um grupo de WhatsApp por meio do qual pudemos acompanhar as ações que tutores de cães soropositivos protagonizavam em situações onde o Estado não chegava ou ao menos não correspondia às suas expectativas.

O grupo acompanhado é formado por tutores, protetores, médicos veterinários e pesquisadores interessados no tema Leishmaniose Visceral. Atualmente, ele conta mais de 220 membros, não apenas de Porto Alegre, mas também de outras regiões do país, sobretudo de regiões epidêmicas, como dos Estados de Minas Gerais, Ceará, Piauí e também do Distrito Federal. As queixas sobre o aumento dos casos de Leishmaniose vinham de toda parte. Era comum associarem a aparecimento de casos com as denúncias de falta de saneamento básico, sobretudo onde o esgoto corre a céu aberto. Essas denúncias de falta de políticas públicas de saneamento básico contrastavam com a vontade do poder público de praticar a eutanásia de cães, como medida de controle da doença nestas mesmas áreas.

Quando destacávamos no grupo algumas das ações que a Secretaria Municipal de Saúde de Porto Alegre protagonizava, o debates quase sempre repercutiam em forma de protesto pela distância entre o que o poder público oferece e aquilo que é demandado por quem vive a Leishmaniose com uma realidade cotidiana. Para a maior parte de quem se envolvia nestes debates, as políticas públicas para o controle da Leishmaniose deveriam combater mais o mosquito do que os cães; fortalecer a educação ambiental e promover vacinação em massa aos moldes do que se pratica com raiva canina. Também deveria haver, segundo os debates no grupo, algum tipo de programa de distribuição gratuita de coleiras nas comunidades de baixa renda, além da aplicação de inseticidas e políticas de saneamento mais equânimes. Além disso, era preciso debater com o poder público a isenção dos altos impostos praticados sobre os produtos antileishmaniose, como coleiras e medicamentos como o Meltiforan. Finalmente, os tutores dos animais quase sempre reclamam respeito para com a sua decisão de os considerarem como parte de sua família, ressoando inúmeros trabalhos que exploram o parentesco multiespécie por exemplo, Govindrajan (2018) ou Osório (2015) - ao invés de simplesmente aceitar o tratamento que lhes era dedicado por parte das autoridades, como sendo ameaças à saúde pública.

Amplamente, o que se notava era que os tutores participantes do grupo sentiamse abandonados pelo poder público. Eles tinham que escolher, digamos assim, entre permitir a eutanásia dos animais ou deixa-los morrer por falta de suporte para o seu cuidado. Essa situação vinha ao encontro do que Lewgoy, Sordi e Pinto (2015, p.79) apontaram como sendo um paradoxo - o de que "os animais domésticos de companhia estão entre os menos protegidos pelas ações governamentais, na medida em que o 
crescimento dos movimentos de defesa dos animais foi acompanhado de uma desresponsabilização das atribuições do poder público". E no caso da Leishmaniose Visceral Canina, este problema se agravava quando somada a uma profunda negligência do Estado, sobretudo com os mais carentes e em situação de vulnerabilidade social, cujos os próprios humanos não possuem direitos respeitados, quanto mais os animais em sua posse.

Segata (2016) também abordou em sua pesquisa sobre os mosquitos da dengue algo muito parecido com o que era discutido no grupo em análise - a questão da higienização da cidade, a invisibilização da pobreza e o risco a ela associado. Quase sempre, como mostra Segata (2016) em sua pesquisa sobre políticas da dengue, as pessoas pobres são acusadas de provocarem as situações de risco, associado a facilitação de criadouros de vetores. Mas, o ponto é que há que se pensar nos sistemas de exclusão que operam em favor dessas situações, já que muitas das ações do poder público "atuam por meio da naturalização da pobreza como condição associada ao risco" . Mais precisamente,

[...] as políticas da ciência e do Estado aos poucos foram deslocando suas práticas, como aquelas centradas na doença e materializadas nas reformas urbanas, para se concentrarem nos mosquitos e na produção da vulnerabilidade. Diferentemente da febre amarela, descrita como uma doença socialista, a dengue é conhecida como a doença da pobreza. Ao invés de reformas, ela produziu periferias, morais e geográficas, na medida em que as políticas de controle do mosquito passaram a operar como barricadas que isolam e protegem as porções mais nobres das cidades (SEGATA, 2016, p.287).

A atual política para o controle do reservatório canino da Leishmaniose Visceral é talhada para a nobreza tendo em vista que animais das periferias, sem tutores, não são tutelados pelo Estado e, tão logo, seu destino tem sido à morte. Entende-se que assim não contribuirão para "espalhar a doença" independente de sua condição física e do adiantamento da doença. Aliás, o recolhimento e eutanásia de cães assintomáticos é uma prática em vários municípios brasileiros, segundo o relato do grupo que foi foco desta pesquisa e estamos longe ainda de uma preocupação de que estes seres sejam reconhecidos como parte do círculo familiar humano.

Marzochi et al. (2014) ecoam as críticas de tutores sobre a redução das políticas de Leishmaniose ao controle de reservatórios caninos. A estratégia de eliminação de cães tem produzido, segundo eles, resultados conflitantes, especialmente se considerado o fato de que o diagnóstico da doença é motivo de discórdia até mesmo entre a 
comunidade científica, tendo em vista o elevado número de falsos positivos. Os autores explicam que estudos entre cães sororreagentes revelou que dos $40 \%$ que apresentavam sinais clínicos da doença e que foram acompanhados pelo período de 1 ano, 88\% evoluíram para óbito e $8 \%$ permaneceram estáveis. Entre os $60 \%$ assintomáticos, após o mesmo período de acompanhamento, $52 \%$ apresentaram negativação sorológica, $12 \%$ continuaram estáveis e $18 \%$ tornaram-se doentes e $18 \%$ morreram no final do período. Eles indicam que metade dos cães soropositivos assintomáticos, mas com indicação de eutanásia, podem se tornar soronegativos, sendo difícil de definir se por falsopositividade ao teste ou por cura espontânea (Marzochi et al., 2014, p.455). Outro aspecto considerados por Marzochi et al. (2014) são os testes que são realizados para afirmar a positividade para os cães visto que o teste sorológico ou teste rápido possui chance de $5 \%$ a $10 \%$ de falso-positividade e não definem o grau de parasitismo, a presença da doença nem o potencial de transmissão do cão para o inseto vetor. Dizem ainda que os testes clássicos Rifi e Elisa podem apresentar reações cruzadas com as infecções caninas por L. braziliensis cujas endemias se superpõem no Nordeste, Sudeste e Sul do Brasil, assim como o Trypanossoma cruzi e o recém-descoberto Trypanossoma caninum. Nesta linha de discussão, muitos relatos no grupo também citaram que a vacinação canina muitas vezes é "vendida" pelos médicos veterinários como sendo $100 \%$ garantida - o que não é verdade. No grupo de tutores que participei alguns mencionaram ter vacinado seus cães e mesmo assim houve acometimento e futuro diagnóstico positivo, o que gerava ainda mais controvérsias sobre a segurança dos testes, já que poderiam reagir à própria vacinação ${ }^{2}$.

Estes desconfortos em relação as políticas para a Leishmaniose que repercutiam nos grupo de WhatsApp e que vinham de diversas partes do Brasil também eram visíveis em Porto Alegre-RS. As críticas firmavam apenas um consenso: o de que atualmente não há uma política de Controle da Leishmaniose Visceral Canina, mas um controle do reservatório canino. Nestes termos atuais, os cães são renegados a segundo plano, estando a serviço do homem, reafirmando a política antropocêntrica que a saúde pública sempre manifestou. Este é um dos principais motivos de mobilização de ações civis, especialmente aquelas protagonizadas pelos grupos que se autodenominam como sendo da proteção animal.

\footnotetext{
2 Mazorchi et al. (2014) adentram à crítica de que as vacinas caninas atualmente disponíveis no mercado não demonstram efetividade, uma vez que cães vacinados de áreas endêmicas se infectam e apresentam Leishmania na pele. Complementam que do ponto de vista do controle a vacinação pode ser uma garantia maior pois não evita a infecção e a doença se manifesta de forma mais branda, o cão ainda é fonte de infecção, agradando os proprietários, remunerando veterinários e conferindo lucro aos laboratórios produtores.
} 
Conforme sugere Osório (2017), a proteção animal possui dois eixos, um emocional e um moral. O emocional, é sobremaneira formado pelas noções de amor, sofrimento, sensibilidade e coração. O segundo, o moral, é formado pelas noções de missão, obrigação, dignidade, respeito, consideração, responsabilidade, proteção, defesa, ajuda, salvamento, solidariedade e educação. Animais que convivem com humanos como membros de família são sujeitos de amor e que exigem responsabilidade. O Estado é raro para estes animais e também para os humanos especialmente em muitos dos casos que acompanhamos nas zonas periféricas de Porto Alegre-RS. Postos de saúde e atenção básica são escassos. Falta saneamento e recursos financeiros para tratamentos especializados. Mas, como costumávamos ouvir, "não falta amor nem solidariedade". Do nosso ponto de vista, esta disposição para o cuidado de cães adoecidos não poderia ser reduzida, como faziam algumas autoridades de saúde, a uma simples romantização extravagante; um exagero arriscado e irresponsável de quem "acha que vai eliminar a doença com amor". O trabalho de resgatar animais doentes da rua, acompanhar a melhora, mas também a morte, a busca de tratamentos alternativos, recursos financeiros ou médicos veterinários voluntários para seguir cuidando do cães, nos mostrava que a atividade política não poderia se resumir àquilo que era pensado e praticado dentro dos espaços institucionais. Ela também acontecia pelas ações civis organizadas - sejam Organizações Não-Governamentais (ONGs), sociedades civis ou como é o caso mais propriamente analisado na pesquisa, o de grupos de proteção animal. Tratava-se de uma política motivada pelo afeto, pela vontade de chegar aonde o Estado não chegava.

\section{Considerações finais}

Neste breve trabalho buscamos apresentar algumas dificuldades de implementação de políticas eficientes para o controle da Leishmaniose. Em linhas gerais, elas se relacionam às dificuldades de infraestrutura, água potável e coleta de lixo e moradia, bem como à inexistência política públicas de cuidado com animais comunitários, sobretudo entre famílias de baixa renda. Mas, também se tornam evidente as dificuldades de gerir certo incômodo cada vez mais crescente com o o modo como nos relacionamos com ambientes e com os animais, deixando de relega-los, simplesmente a uma esfera distinta daquela do mundo social, concebido como humano. No caso em questão, o cão doméstico urbano, acometido por Leishmaniose se tornou uma espécie de emblema da encruzilhada moral de difícil equacionamento diante da tradição sanitária-epidemiológica: de reservatório de doença facilmente descartável por 
meio da eutanásia ele se converteu em membro de família e sujeito de reivindicação de direitos e garantias por meio de políticas públicas mais inclusivas.

Outro ponto que buscamos traçar neste artigo é o modo como o alcance do Estado ainda é limitado em termos de políticas, digamos assim, multiespécie - ou seja, que pensem a relação de saúde-doença com um fenômeno que implica o bem estar de humanos, animais e dos ambientes que juntos constroem e partilham. $\mathrm{O}$ caso de Porto Alegre-RS nos mostrou o quanto que as preocupações com a Leishmaniose Visceral Canina começaram a ter forma em termos de uma agenda de políticas públicas apenas à medida em que passaram a ameaçar a saúde humana, com casos confirmados e sobretudo com óbitos. Os casos que vitimavam animais até então eram silenciados e assim o continuaram sendo, repercutindo, de muitas formas, a negligência com a doença.

Além disso, pudemos perceber que a Leishmaniose Visceral Canina ainda é uma doença bastante desconhecida em Porto Alegre-RS. Exceto por agentes de saúde, médicos veterinários e pessoas que, em algum momento se envolveram com o tema, para muita gente o adoecimento de seus cães era um fenômeno desconhecido, confundido com envelhecimento, sarna, praga ou mal da rua. A própria OMS considera a Leishmaniose como uma das seis doenças mais negligenciadas no mundo. A respeito disto, Araújo, Moreira e Aguiar (2013) abordam a questão do silêncio sobre a doença na saúde pública, como sendo a não comunicação pública uma das condições do negligenciamento de enfermidades e de suas populações afetadas. Os autores, citando a OMS, tratam que:

O negligenciamento de uma doença - que evoca o discurso de segregação, periferia e esquecimento, seja pela indústria farmacêutica, pelos governos ou pelos sistemas de saúde - significa também, de forma concomitante e inextrincável, o negligenciamento das populações vitimadas por estes agravos. Pré-existente e, ao mesmo tempo, intensificado pela ocorrência de agravos negligenciados, o negligenciamento das populações está correlacionado à pobreza, num círculo vicioso que vigora para um sexto da população mundial. (Araújo; MOREIRA; AGUIAR, 2013, p.03).

As leishmanioses, não apenas em Porto Alegre-RS, mas de um modo geral, são doenças negligenciadas pois pouco se comunica e se age reativamente aos seus casos. A questão das comunidades assoladas pela enfermidade caminham lado a lado com a falta de políticas de saneamento básico, habitação, acesso à saúde e qualidade nutricional. Lindoso e Lindoso (2009, p.247) avalia que a existência da pobreza está 
extremamente ligada com a ocorrência de doenças tropicais negligenciadas e as relaciona com o Índice de Desenvolvimento Humano (IDH) dos países em que elas ocorrem e acrescenta:

O Brasil é o $70^{\circ}$ país no ranking do IDH e concentra nove das 10 principais doenças tropicais consideradas negligenciadas pela OMS. Leishmanioses, tuberculose, dengue e hanseníase ocorrem em quase todo o território do Brasil. Mais de $90 \%$ dos casos de malária ocorrem na região norte e há surtos de filariose linfática e oncocercose. As regiões norte e nordeste apresentam o menor IDH e concentram o maior número das DTNs. Essas doenças são consideradas negligenciadas devido à falta de investimento no desenvolvimento de novas drogas e vacinas e também pela pouca eficácia dos programas de controle. Um problema preocupante em relação às DTNs é a co-infecção com HIV, que favorece manifestações clínicas graves e falência terapêutica (Lindoso; Lindoso, 2009, p.247).

O ditado popular é bem cabível neste caso: "quem não é visto não é lembrado". Nisto se incluem os moradores em áreas de risco que não tem acesso às políticas públicas como seus animais adoecidos. Na lógica dos apagamentos, as doenças e as pessoas negligenciadas, quanto menos faladas, menos existem. Quanto menos existem, menos recursos e esforços públicos demandam para o seu bem estar. Assim, de um lado a Leishmaniose é considerada uma doença negligenciada porque é de certa forma esquecida pelo Estado e de outro porque não há formas amplificadas de uma educação para o seu reconhecimento e cuidado já que se desenvolve entre populações humanas igualmente desprezadas. Em outras palavras, a despeito das parcas e controversas políticas atualmente disponíveis, as histórias com a Leishmaniose ainda têm sido escritas por aqueles animais e seus companheiros humanos que partilham, de fato, "uma vida de cão".

\section{Sharing a DOG'S LIFe: PUblic POLICIES AND CANINe VISCERAL LEISHMANIASIS}

ABSTRACT: This paper brings some introductory lines to analyze public policies for Canine Visceral Leishmaniasis. Based on the case of Porto Alegre, RS, Brazil, we tried to show that there is a silencing of canine suffering in the evidence that public policies for Leishmaniasis start to be constituted only when the disease threatens human lives. Likewise, we show how policies of coexistence are produced and experienced much more by civil initiatives - almost always marginalized and even against public policies 
thought and executed by the government, when certain populations of dogs and humans are neglected by the public power.

KEYWORDS: Canine Visceral Leishmaniasis. Public Policies. Neglected Diseases. Multispecies Health.

\section{Compartiendo la vida de un PerRo: Políticas públicas y LEISHMANIOSIS CANINA VISCERAL}

RESUMEN: Este artículo presenta algunas líneas introductorias de una exploración sobre las politicas públicas para la Leishmaniosis Visceral Canina. A partir del caso de Porto Alegre tratamos de mostrar que hay un silenciamiento del sufrimiento canino en la evidencia de que las políticas públicas para la Leishmaniasis se constituyen sólo cuando la enfermedad amenaza las vidas humanas. Asimismo, mostramos cómo las políticas de convivencia se producen y se viven mucho más entre iniciativas civiles casi siempre al margen e incluso contra las politicas públicas pensadas y ejecutadas por el Estado, cuando determinadas poblaciones de perros y humanos son desatendidas por el poder público.

PALABRAS CLAVE: Leishmaniasis Visceral Canina. Políticas públicas. Enfermedades olvidadas. Salud multiespecie.

\section{REFERÊNCIAS}

ARAÚJO, Inesita Soares; MOREIRA, Adriano De Lavor; AGUIAR Raquel. Doenças negligenciadas, comunicação negligenciada. Apontamentos para uma pauta política e de pesquisa. RCIIS - Revista Eletrônica de Comunicação, Informação e Inovação em Saúde, Rio de Janeiro, vol. 6, n. 4, Suplemento, Fev. 2013, p.01-15. Disponível em: https://www.reciis.icict.fiocruz.br/index.php/reciis. Acesso em: 17 out. 2020.

BENCHIMOL, Jaime; JOGAS JUNIOR, Denis Guedes. Uma história das leishmanioses no novo mundo. Rio de Janeiro: Fino Traço/Fiocruz, 2020.

CANOFRE, Fernanda. Defensores questionam decisão da Prefeitura de eutanasiar cães com suspeita de leishmaniose. Sul21. Publicado em 6 de maio de 2017. Disponível em: https://www.sul21.com.br/ultimas-noticias/geral/2017/05/defensores-questionam-decisao-daprefeitura-de-eutanasiar-caes-com-suspeita-de-leishmaniose/. Acesso em: 17 out. 2020. 
GOVINDRAJAN, Radhika. Animal intimacies: interspecies relatedness in India's Central Himalayas. Chicago: The University of Chicago Press, 2018.

LEWGOY, Bernardo; MASTRANGELO, Andrea; BECK, Luiza. Tanatopolítica e Biossegurança: dois regimes de governo da vida para a Leishmaniose Visceral Canina no Brasil. Horizontes Antropológicos, Porto Alegre, ano 26, n. 57, maio/ago. 2020, p.145-176. Disponível em: https://www.scielo.br/pdf/ha/v26n57/1806-9983-ha-26-57-145.pdf. Acesso em: 18 out. 2020 .

LEWGOY, Bernardo; SORDI, Caetano; PINTO, Leandra Oliveira. Domesticando o Humano: para uma antropologia moral da proteção animal. Ilha Revista de Antropologia, Florianópolis, vol. 17, n. 2, p.075-100, 2015.

LINDOSO, José Angelo; LINDOSO, Ana Angélica. Doenças tropicais negligenciadas no Brasil. Revista do Instituto de Medicina Tropical de São Paulo. São Paulo, vol. 51, n. 5, p.247-253, 2009.

MARZOCHI Mauro C. A; MARZOCHI Keyla B. Feldman; FAGUNDES, Aline; CONCEIÇÃO-SILVA, Fátima. A questão do controle das leishmanioses no Brasil. In: CONCEIÇÃO-SILVA, Fátima; ALVES, Carlos Roberto. (org.). Leishmanioses do continente americano. Rio de Janeiro: Fiocruz, 2014, p.432-463.

OSORIO, Andrea. Conversões e predisposições à proteção de animais de rua: vocações, sensibilidades e moralidades. Horizontes Antropológicos, Porto Alegre, ano 23, n. 48, 2017 , p.253-274.

OSORIO, Andrea. Mãe de gato? Reflexões sobre o parentesco entre humanos e animais de estimação. V Reunião Equatorial de Antropologia e XV Reunião de Antropólogos do Norte-Nordeste. Maceió: Anais do Evento, 2015.

KLEIN, Samantha. Prefeitura revoga contrato com clínica e desiste de sacrificar até 300 cães em Porto Alegre. Correio do Povo. Publicado em 14 de julho de 2017. Disponível em: https://www.correiodopovo.com.br/not\%C3\%ADcias/pol\%C3\%ADtica/prefeitura-revogacontrato-com-cl\%C3\%ADnica-e-desiste-de-sacrificar-até-300-cães-em-porto-alegre-1.236038. Acesso em: 18 out. 2020.

ROQUE, André Luis Rodrigues; JANSEN, Ana Maria. "Hospedeiros e reservatórios de Leishmania s.p e sua importância na manutenção dos ciclos de transmissão nos ambientes silvestre e sinantrópico”. In: CONCEIÇÃO-SILVA, Fátima; ALVES, Carlos Roberto. (org.). Leishmanioses do continente americano. Rio de Janeiro: Fiocruz, 2014, p.233-257. 
PORTO ALEGRE. Prefeitura Municipal de Porto Alegre; Coordenadoria Geral de Vigilância em Saúde. Monitoramento Ambiental - Leishmaniose. Disponível em:

http://www2.portoalegre.rs.gov.br/cgvs/default.php?p_secao=1009. Acesso em: 18 out. 2020a.

PORTO ALEGRE. Prefeitura Municipal de Porto Alegre; Secretaria Municipal de Saúde.

Relatório de Gestão. Disponível em:

http://www2.portoalegre.rs.gov.br/sms/default.php?p_secao=895. Acesso em: 18 out. 2020 b.

PORTO ALEGRE. Prefeitura Municipal de Porto Alegre; Secretaria Municipal de Saúde.

Carta Aberta à População de Porto Alegre sobre Leishmaniose Visceral Humana. 2017a, mimeo.

PORTO ALEGRE. Prefeitura Municipal, Secretaria Municipal de Saúde. Plano Municipal de Intensificação das Ações de Vigilância e Controle da Leishmaniose Visceral. 2017b.

Disponível em:

http://lproweb.procempa.com.br/pmpa/prefpoa/cgvs/usu_doc/lvh_plano_de_intensificacao_fina l.pdf. Acesso em: 18 out. 2020.

PORTO ALEGRE. Prefeitura Municipal de Porto Alegre; Secretaria Municipal de Saúde.

Relatório Anual de Gestão. 2016. Disponível em:

http://lproweb.procempa.com.br/pmpa/prefpoa/sms/usu_doc/rag_final_2016.pdf. Acesso em: 17 out. 2020 .

SEGATA, Jean. El mosquito-oráculo y otras tecnologías. Tabula Rasa, Bogotá, vol. 32, 2019, p.103-125. Disponível em: http://dx.doi.org/10.25058/20112742.n32.06. Acesso em: 18 out. 2020 .

SEGATA, Jean. A doença socialista e o mosquito dos pobres. Iluminuras, Porto Alegre, vol. 17, 2016, p. 372-389.

VARGAS, Elisa Oberst. Mosquitos, armadilhas e vírus: etnografia de uma política pública de controle ao aedes aegypti. 2018. Dissertação (Mestrado em Antropologia Social) - Programa de Pós-Graduação em Antropologia Social, Universidade Federal do Rio Grande do Sul, Porto Alegre, 2018.

Recebido em 23/08/2020.

Aprovado em 13/09/2020. 